Article

\title{
Thermal and Mechanical Behavior of Hybrid Polymer Nanocomposite Reinforced with Graphene Nanoplatelets
}

\author{
Minh-Tai Le ${ }^{1,2}$ and Shyh-Chour Huang ${ }^{2, *}$ \\ ${ }^{1}$ Faculty of Mechanical Engineering, Ho Chi Minh City University of Technology and Education, \\ No.1, Vo Van Ngan, Thu Duc District, Ho Chi Minh City 70000, Vietnam; \\ E-Mail: tailm@hcmute.edu.vn \\ 2 Department of Mechanical Engineering, National Kaohsiung University of Applied Sciences, \\ 415 Chien Kung Road, Sanmin District, Kaohsiung 80778, Taiwan \\ * Author to whom correspondence should be addressed; E-Mail: shuang @cc.kuas.edu.tw; \\ Tel.: +886-7-3814526 (ext. 5313); Fax: +886-7-3831373.
}

Academic Editor: Teen-Hang Meen

Received: 21 June 2015 / Accepted: 19 August 2015 / Published: 24 August 2015

\begin{abstract}
In the present investigation, we successfully fabricate a hybrid polymer nanocomposite containing epoxy/polyester blend resin and graphene nanoplatelets (GNPs) by a novel technique. A high intensity ultrasonicator is used to obtain a homogeneous mixture of epoxy/polyester resin and graphene nanoplatelets. This mixture is then mixed with a hardener using a high-speed mechanical stirrer. The trapped air and reaction volatiles are removed from the mixture using high vacuum. The hot press casting method is used to make the nanocomposite specimens. Tensile tests, dynamic mechanical analysis (DMA) and thermogravimetric analysis (TGA) are performed on neat, $0.2 \mathrm{wt} \%, 0.5 \mathrm{wt} \%$, $1 \mathrm{wt} \%, 1.5 \mathrm{wt} \%$ and $2 \mathrm{wt} \%$ GNP-reinforced epoxy/polyester blend resin to investigate the reinforcement effect on the thermal and mechanical properties of the nanocomposites. The results of this research indicate that the tensile strength of the novel nanocomposite material increases to $86.8 \%$ with the addition of a ratio of graphene nanoplatelets as low as $0.2 \mathrm{wt} \%$. DMA results indicate that the $1 \mathrm{wt} \%$ GNP-reinforced epoxy/polyester nanocomposite possesses the highest storage modulus and glass transition temperature $\left(\mathrm{T}_{\mathrm{g}}\right)$, as compared to neat epoxy/polyester or the other nanocomposite specimens. In addition, TGA results verify thethermal stability of the experimental specimens, regardless of the weight percentage of GNPs.
\end{abstract}


Keywords: nanocomposite; graphene nanoplatelets; epoxy; unsaturated polyester; tensile strength; thermal conductivity; morphology

\section{Introduction}

Graphene nanoplatelets (GNPs) are a type of filler in the new generation of reinforced materials. Producing high-purity and large amounts of GNPs has a highcost, and because of the issues related to their stability during the process of fabricating nanocomposite materials, researchers have recommended using them in a pristine state, i.e., not to be handled as a functional group [1].

Relating to the matrix for the construction of the composite, thermoset epoxy is the top choice because of its excellent thermomechanical properties, which contribute to the successful fabrication of advanced nanocomposite materials [2,3]. Another type of thermoset polymer used to reinforce as well as modify a material's performance is polyester. With its high thermal and mechanical properties, it is both simpler and cheaper to use than epoxy, and polyester can be used as the second matrix phase mixed with epoxy to create a general matrix structure of composite materials [4-6].

There are studies in which GNPs were used as fillers to enhance the properties of the epoxy matrix $[7,8]$. The new generation of hybrid composite materials with versatile mechanical, thermal and electrical properties are of particular interest to researchers $[9,10]$.

The thermal conductivity of epoxy nanocomposites having 0.5 and $1 \mathrm{wt} \%$ of silica-coated MWCNTs was found to be enhanced by $51 \%$ and $67 \%$, respectively, by Cui et al. [11]. Viswanath et al. [12] presented a thermomechanical and electrical study of epoxy/hyperbranched polyester. Rahman et al. [13] optimized the mechanical properties of epoxy reinforced with E-glass and amino-functionalized MWCNTs. The MWCNTs were aligned in the epoxy resin to achieve the required properties by Park et al. [14]; the thermal conductivity of epoxy/MWCNT nanocomposites at room temperature (RT) was observed to be $55 \mathrm{~W} / \mathrm{mK}$; the stretched MWCNT-epoxy sheet showed a value of $100 \mathrm{~W} / \mathrm{mK}$, whereas pure epoxy was $0.11 \mathrm{~W} / \mathrm{mK}$ at RT.

In most previous studies, thermoset polymers did factor in the critical investigation of the performance of hybrid matrix materials made with epoxy and polyester. In this research, the added filler of GNPs was used to reinforce the tensile strength and thermal conductivity of the hybrid epoxy/polyester composite. The GNPs were mixed at different weight percentages with epoxy and polyester using high intensity ultrasonication. The resulting experimental specimens were obtained by means of the hot press casting method.

The primary interest of this paper was to characterize the effect of graphene nanoplatelets on the thermal and mechanical properties of the epoxy/polyester hybrid composite. Tensile tests were performed to evaluate the mechanical performance, and thermogravimetric analysis (TGA) and dynamic mechanical analysis (DMA) were carried out to evaluate the thermal properties. Additionally, the morphological characteristics of the surface structure of the nanocomposite samples in the tensile test were observed by a scanning electron microscope (SEM). The important contribution of this study is the successful fabrication of a hybrid matrix nanocomposite material of thermoset resins reinforced with the GNP filler. The nanocomposite specimens fabricated at a low cost evidenced high mechanical strength, 
good thermal conductivity and stability, making them suitable for applications in the manufacturing of components for electronic circuit boards and transportation.

\section{Materials and Methods}

\subsection{Material Preparation}

The graphene nanoplatelets (GNPs) used in this study were Grade 4 (Figure 1), purchased from Cheap Tubes Inc. (Cambridgeport, VT, USA), with an average plate diameter in the range of 1 to $2 \mu \mathrm{m}$ and over $99 \%$ pure. The materials for creating the matrix structure of the composite consisted of epoxy 6620 , hardener AH150 and unsaturated polyester resin (UPR) GC-0421, all purchased from Golden Innovation Business Co. (Taibei, Taiwan). As suggested by the manufacturer, some modification materials were used: an accelerator of cobalt naphthenate (6\%) and a catalyst of methyl ethyl ketone peroxide (MEKP). To easily disperse the GNP filler in the resin, it was necessary to use methyl ethyl ketone (MEK) as a dissolution.

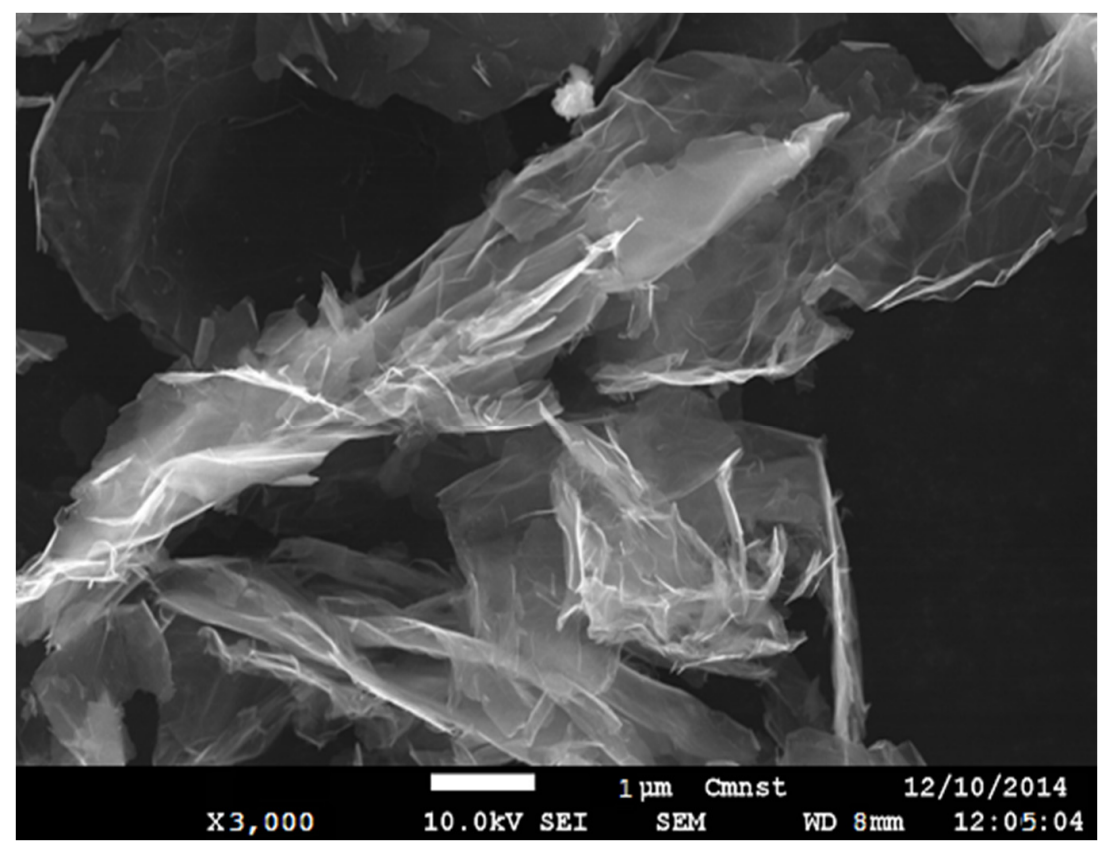

Figure 1. Scanning electron microscope image of pristine graphene nanoplatelets.

Figure $2 \mathrm{a}$ shows the whole process of the experimental specimen preparation. The predetermined amounts of GNPs, epoxy and UPR were mixed together in a suitable beaker. The stipulated amounts of GNP and epoxy/polyester blend were mixed thoroughly with a magnetic stirrer for about $1 \mathrm{~h}$ at a temperature of $60{ }^{\circ} \mathrm{C}$. The beaker was then placed in an ultrasonicator at a high intensity for $1 \frac{1 / 2}{h}$ set at a pulse mode ( $9 \mathrm{~s}$ on/9 s off). An external cooling system was employed by submerging the beaker containing the mixture in an ice bath to avoid the temperature rising during the sonication process. When the process was finished, all agents, including the hardener, accelerator and catalyst, with a weight ratio of 2:1/1/1, were added to the previous epoxy/polyester mixture. An aluminum mold (Figure 2) of the required dimensions was used for the making of samples on par with the American Society for Testing and Materials (ASTM) standard. The mold was covered with a mold-releasing agent so the samples 
could be easily removed. The completed mixture was poured into the mold. The 2-part casting mold was maintained under a pressure of $0.8 \mathrm{MPa}$ for $24 \mathrm{~h}$ at room temperature. To complete the curing process and eliminate residual stresses due to heat, the experimental samples (Figure $3 \mathrm{~b}$ ) were post cured at $90{ }^{\circ} \mathrm{C}$ for $3 \mathrm{~h}$.

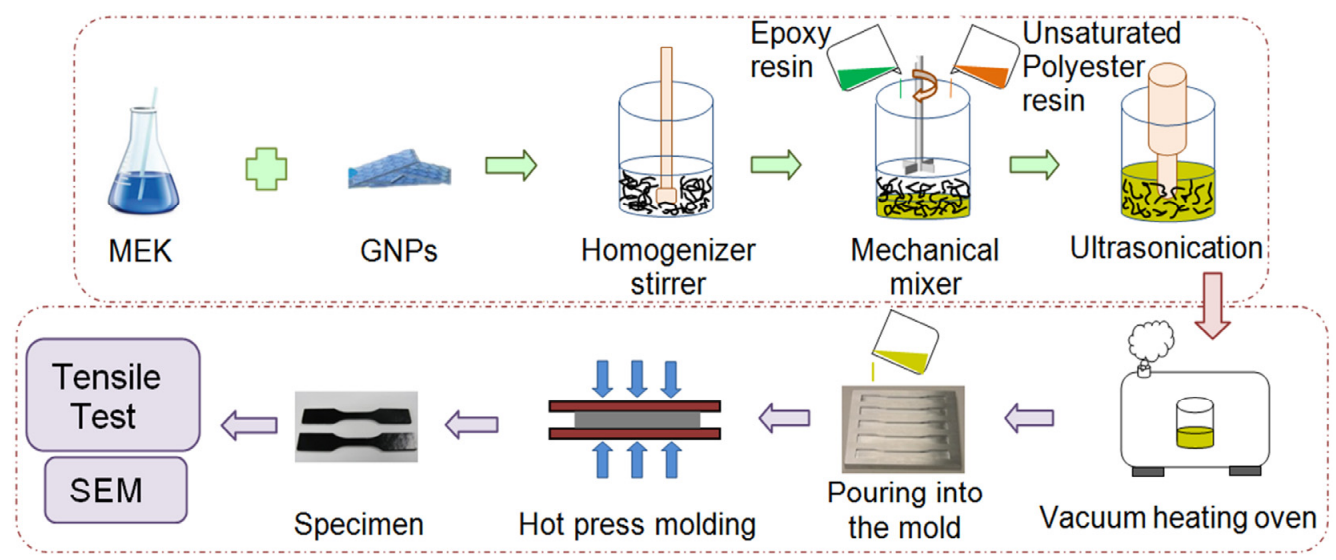

(a)

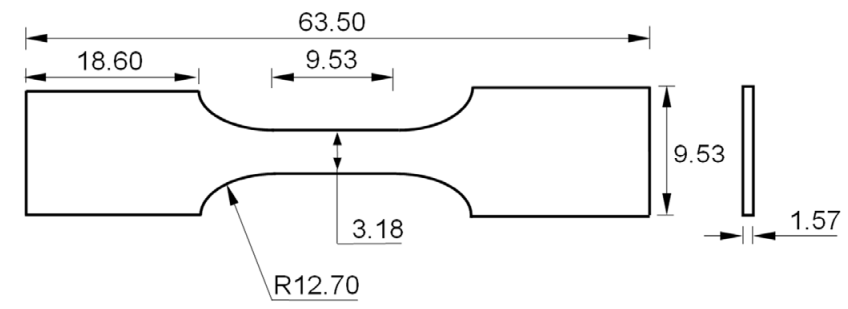

(b)

Figure 2. (a) Schematic showing the manufacturing process of the nanocomposite; (b) dimensions of specimen in ASTM standard Type V (mm).

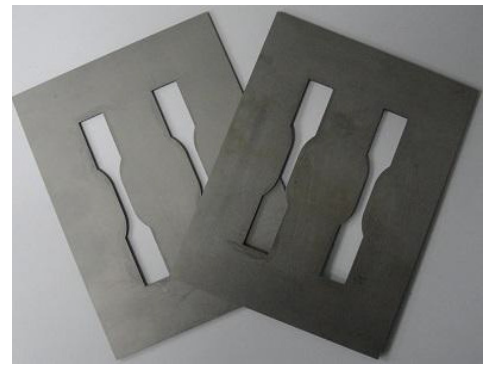

(a)

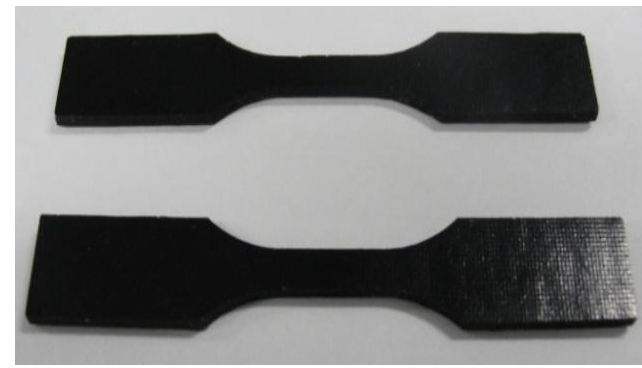

(b)

Figure 3. (a) Aluminum mold; (b) nanocomposite specimens.

\subsection{Mechanical Test}

The experimental set up for the tensile test was done on an Instron 5566-CN2081 machine (Instron Company, Hsinchu, Taiwan) with a standard of ASTM D638 (Type V). The following parameters were set for the experiment: clamp length of $26.3 \mathrm{~mm}$, tensile speed of $0.5 \mathrm{~mm} / \mathrm{min}$ and room temperature of $30{ }^{\circ} \mathrm{C}$. For each content of filler, the tensile test was carried out on at least five specimens; the result was the average value of the five measurements. 


\subsection{Thermal Analysis}

The thermal characteristics of the GNP/epoxy/polyester-blended nanocomposites were studied using dynamic mechanical analysis (DMA) (TA Instruments Co., New Castle, PA, USA) and thermogravimetric analysis (TGA) (TA Instruments Co., New Castle, PA, USA).

DMA was performed using a TA Instruments 2980, operated in the three-point bending mode at a frequency of $1 \mathrm{~Hz}$. The experimental data were obtained at room temperature to $160{ }^{\circ} \mathrm{C}$ at a scanning rate of $10{ }^{\circ} \mathrm{C} / \mathrm{min}$. The specimens for the bending test had the nominal dimensions of $2 \mathrm{~mm} \times 15 \mathrm{~mm} \times$ $6 \mathrm{~mm}$. TGA was used to investigate the thermal decomposition behavior of the nanocomposite blend. Tests were done with a TA Instruments TGA2950 at a heat rate of $10{ }^{\circ} \mathrm{C} / \mathrm{min}$ in a temperature range of 30 to $600{ }^{\circ} \mathrm{C}$. A sample of 5 to $10 \mathrm{mg}$ was used for each run. The weight change was recorded as a function of temperature.

\section{Results and Discussion}

\subsection{Mechnical Properties}

The stress-strain responses of the nanocomposite specimens in the tensile tests are shown in Figure 4. The tensile properties of the nanocomposites at different weight percentages of filler were transformed in a similar way. Initially, the tensile stress increased in a linear style, showing an elastic deformation stage of the material. Then, the stress reached the maximum value and decreased rapidly to the complete failure state. The results of the tensile tests showed the nanocomposite specimens to have an elastoplasticity property and to be slightly brittle.

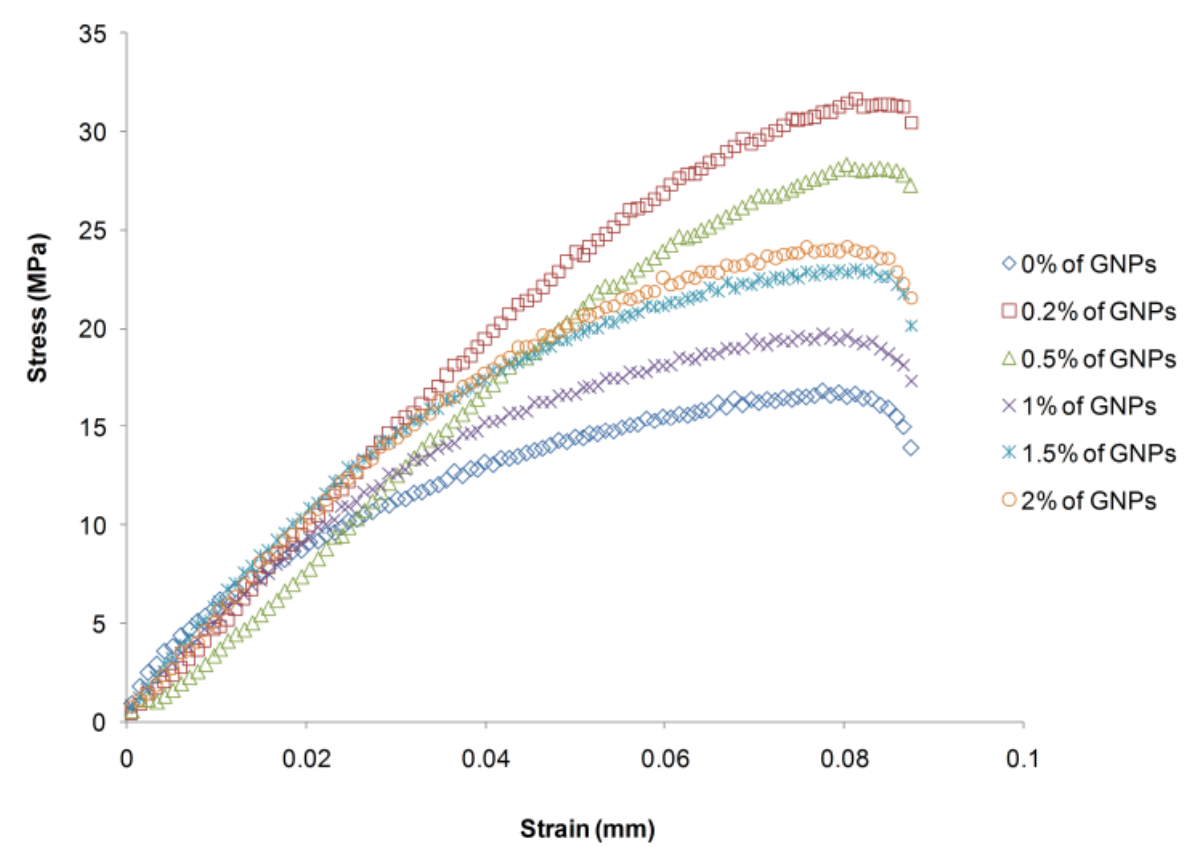

Figure 4. Stress-strain curves from tensile test.

The analysis data of the 30 experiments, achieved using Nexygen Plus software with a high reliability of over 95\%, are shown in Table 1. 
Table 1. Dependence of the tensile strength on the filler ratio of graphene nanoplatelets (GNPs).

\begin{tabular}{cc}
\hline \% of GNPs & Tensile strength (MPa) \\
\hline $0 \%$ & 17.009 \\
$0.2 \%$ & 31.775 \\
$0.5 \%$ & 28.489 \\
$1 \%$ & 19.914 \\
$1.5 \%$ & 18.900 \\
$2 \%$ & 18.492 \\
\hline
\end{tabular}

The dependence of the tensile strength on the filler content of GNPs is shown in Table 1. When the weight percentage of GNPs was in the range of $0 \%$ to $0.2 \%$, the tensile strength of the nanocomposite samples increased rapidly. When the content of GNPs increased to a range of $0.2 \%$ to $1 \%$, the tensile strength decreased sharply. In a weight percentage range of $1 \%$ to $2 \%$, the change in tensile strength was slight. The maximum value of tensile strength was achieved with a GNP content of only $0.2 \%$. This value showed an increase of approximately $86.8 \%$ over the tensile strength of the specimens without added filler. The enhancement of the mechanical properties of the nanocomposites was due to the homogeneous dispersion of the reinforcement material and the good interaction between the reinforcement and the matrix, which was also confirmed by Gojny and Schulte [15].

\subsection{Thermal Properties}

Figure 5 presents the DMA results of the relationship between the storage modulus and temperature with different weight percentages of GNP filler. The plots show the storage modulus as a function of the filler content. With GNP filler increases from $0.2 \%$ to $1 \%$, the storage modulus tended to increase. When the GNP content exceeded $1 \%$, the storage modulus tended to decrease markedly. Here, epoxy/polyester nanocomposite reinforced with $1 \mathrm{wt} \%$ of GNP content achieved an increase of up to $3100 \mathrm{MPa}$ of storage modulus at a temperature of $30^{\circ} \mathrm{C}$.

The loss factor curves $(\tan \delta)$ of all the nanocomposites were obtained by DMA, as shown in Figure 6. The maximum value of the glass transition temperature $\left(\mathrm{T}_{\mathrm{g}}\right)$ was identified in the peak position of $\tan \delta$. This value was observed in the nanocomposite with filler content of $1.5 \%$. As can be seen in Figure 6 , the peak height of $\tan \delta$ decreased with an increase in the GNP weight percentage, while the width of the loss factor showed little variation with the changes in nano-filler content. The peak factor, $\Gamma$, defined as the full width at half maximum of the $\tan \delta$ peak divided by its height, can be qualitatively used to assess the homogeneity of the epoxy/polyester network. The low peak factor of the neat epoxy/polyester blend indicated that the crosslink density and homogeneity of the resin network were high.

Figure 7 shows the thermal conductivity of the epoxy and its nanocomposites prepared by different processing conditions. The thermal conductivity of the $0.2 \mathrm{wt} \%$ GNP sample and $0.5 \mathrm{wt} \%$ GNP was found to be $0.09 \mathrm{~W} / \mathrm{mK}$ and $0.104 \mathrm{~W} / \mathrm{mK}$, respectively, lower than that of the neat epoxy/polyester $(0.12 \mathrm{~W} / \mathrm{mK})$ due to the debonding between the reinforcement and the matrix. It was also observed that the thermal conductivity of the $1 \mathrm{wt} \%$ GNP sample increased with the reinforcement of GNPs, 
and the enhancement was significant as compared to that of the other samples. This enhancement of thermal conductivity was due to the homogeneous dispersion of GNPs in the epoxy/polyester resin and the bonding between them. The enhancement of thermal conductivity was found to be $33.3 \%$ for $1 \mathrm{wt} \%$ GNP sample compared to the neat epoxy/polyester.

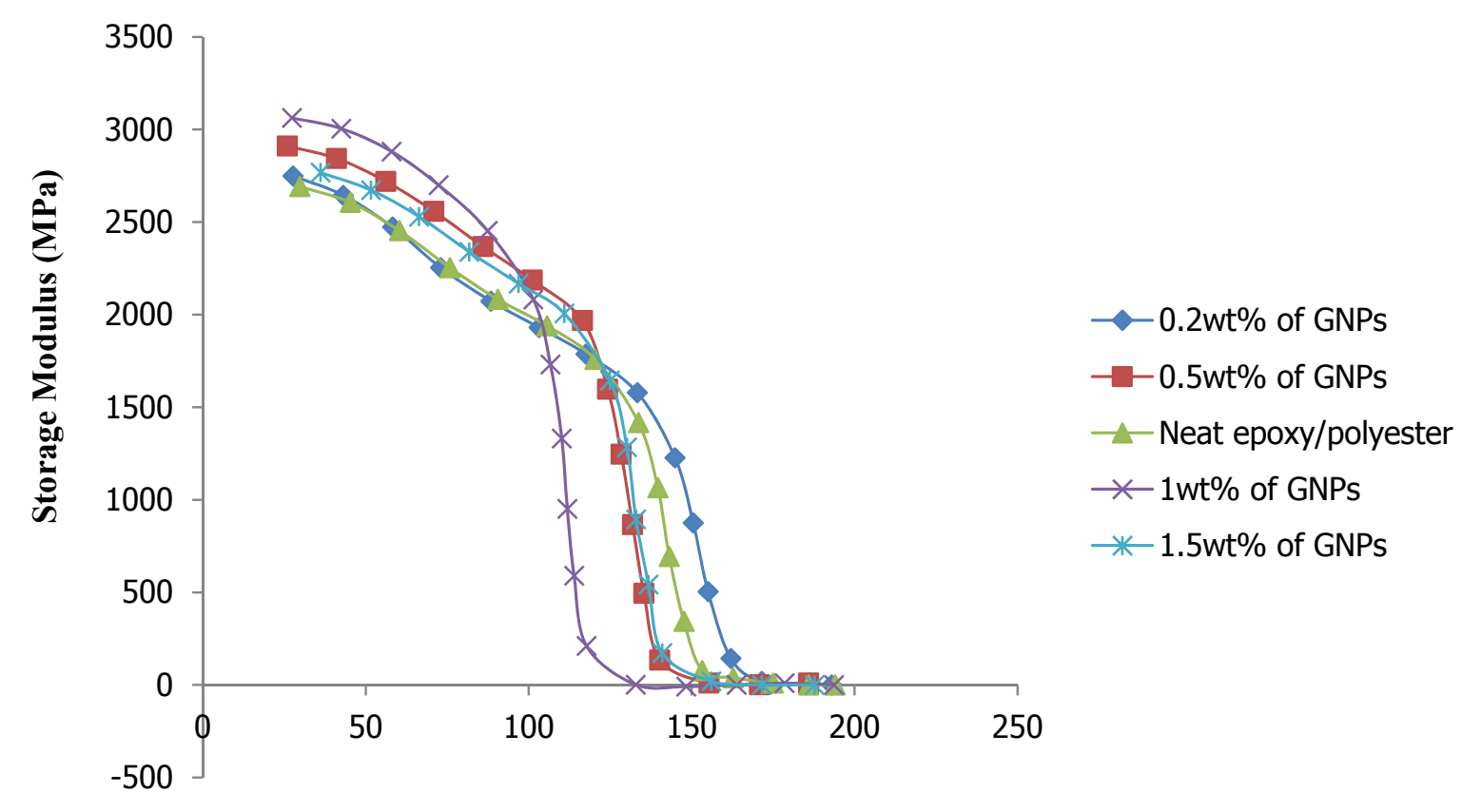

Temperature $\left({ }^{\circ} \mathrm{C}\right)$

Figure 5. Storage modulus vs. temperature plots of GNP/epoxy/polyester nanocomposite.

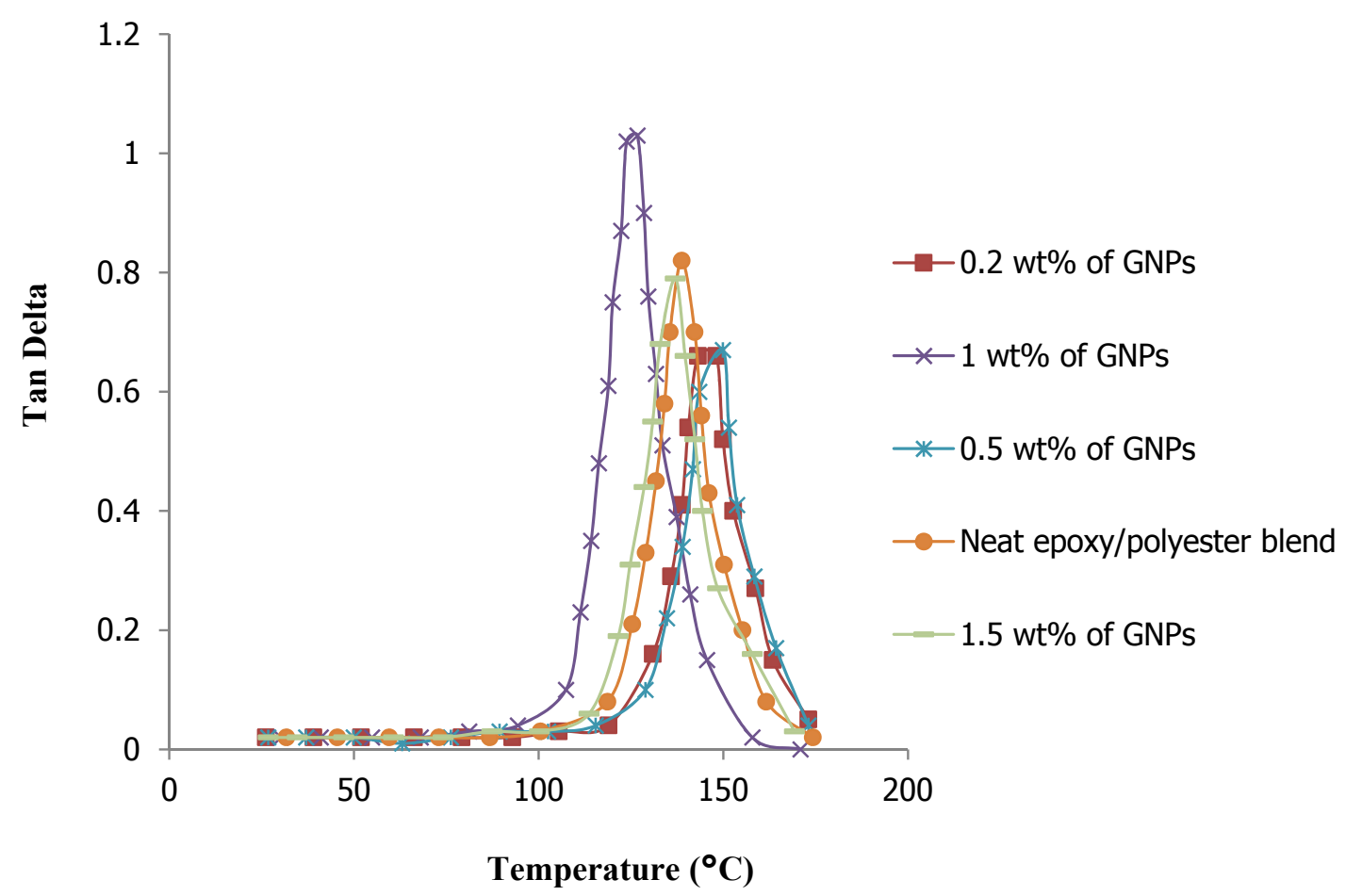

Figure 6. Relationship between the loss factor $(\tan \delta)$ and temperature of GNP-reinforced hybrid composite specimens. 


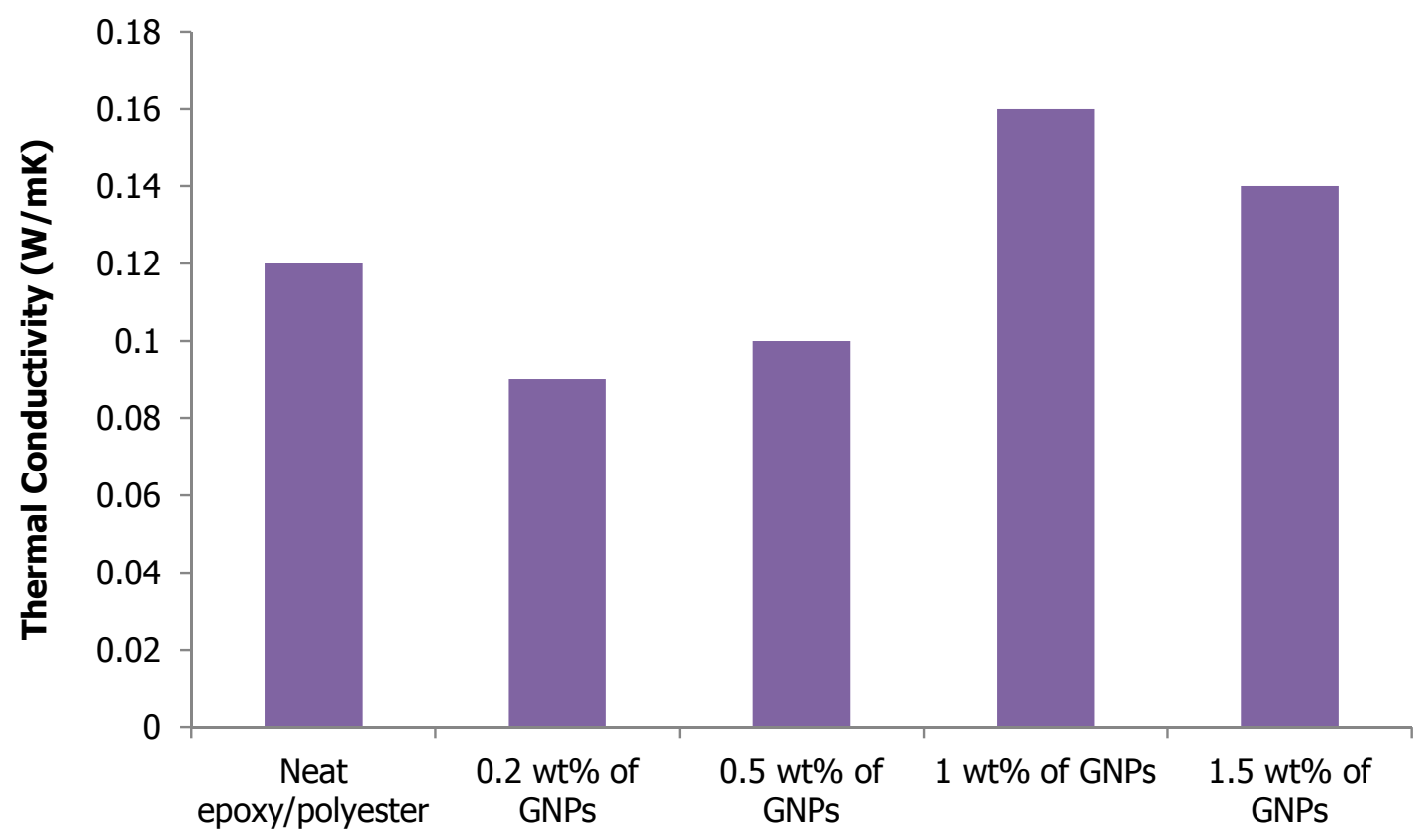

Figure 7. Thermal conductivity of nanocomposites.

Thermogravimetric analysis (TGA) was also performed to evaluate the thermal stability of all the fabricated nanocomposite samples, as shown in Figure 8. These samples were confirmed as having a $48 \%$ weight loss, evidence of the destruction in composite structure when affected by heat. Moreover, as this figure shows, the decomposition temperatures were almost the same for all the nanocomposites in the experiment, which proved that the heat destruction caused to the resulting nanocomposites in this study was not dependent on the content of fillers.

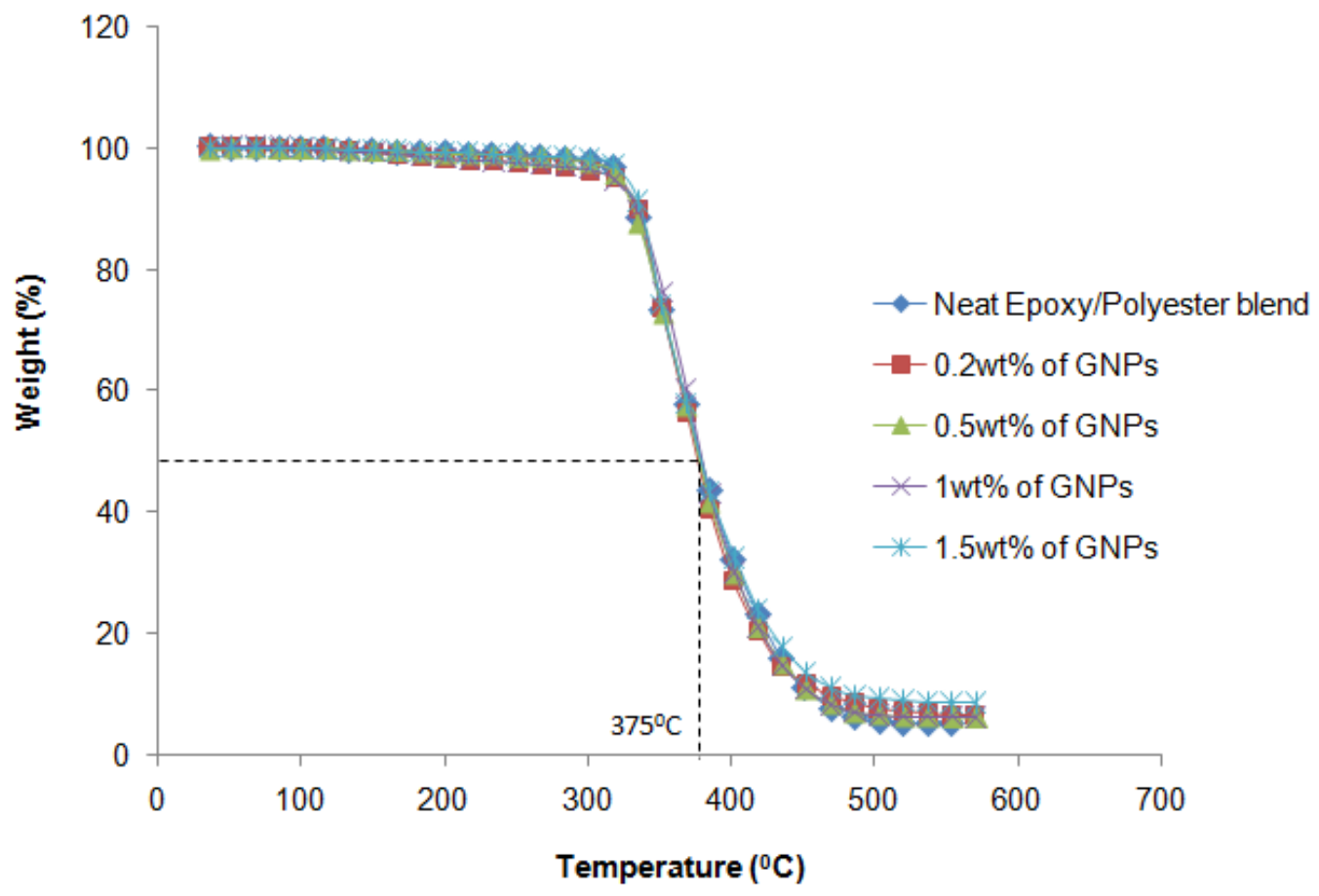

Figure 8. Thermal stability of nanocomposites. 


\subsection{Morphological Characteristics}

Figure 9 shows the results of the morphological structure analysis of the fracture surface using SEM. The observed results were consistent with the obtained data of previous tensile tests. A relatively smooth surface can be seen in Figure 9a for the neat matrix material of epoxy and polyester mix without fillers, while in Figure $9 b$ the rather rough fracture surface of the nanocomposites reinforced by $0.2 \%$ GNP filler is evident in the brittle fracture-style development of this material. The agglomeration of fillers negatively affected the mechanical properties of the nanocomposite. This phenomenon usually occurs when there is a large increase in the filler percentage. Figure 9c shows an SEM image of the $0.2 \%$ GNP-reinforced nanocomposite at a magnification up to 30,000. It can be seen from this image that the GNP filler was completely covered by the matrix phase, indicating a good adhesion between the two structural phases, which contributed to the enhancement of the mechanical properties of the produced nanocomposites.

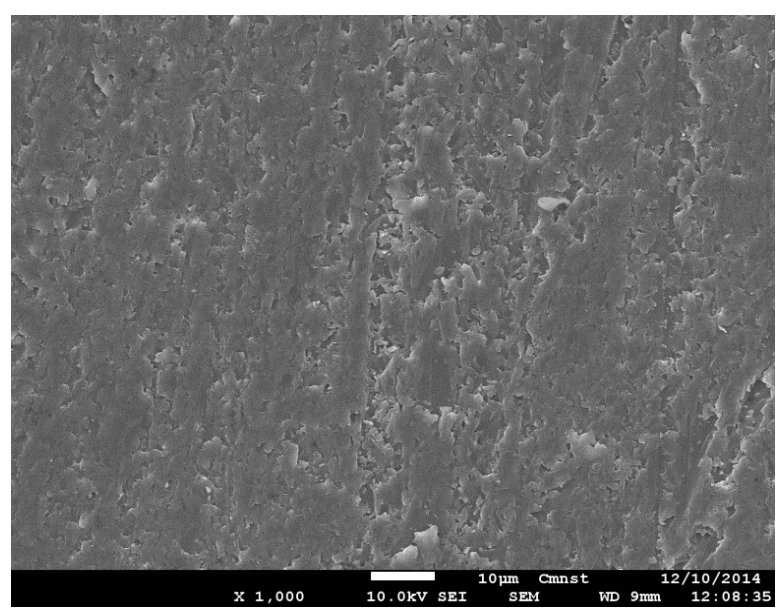

(a)

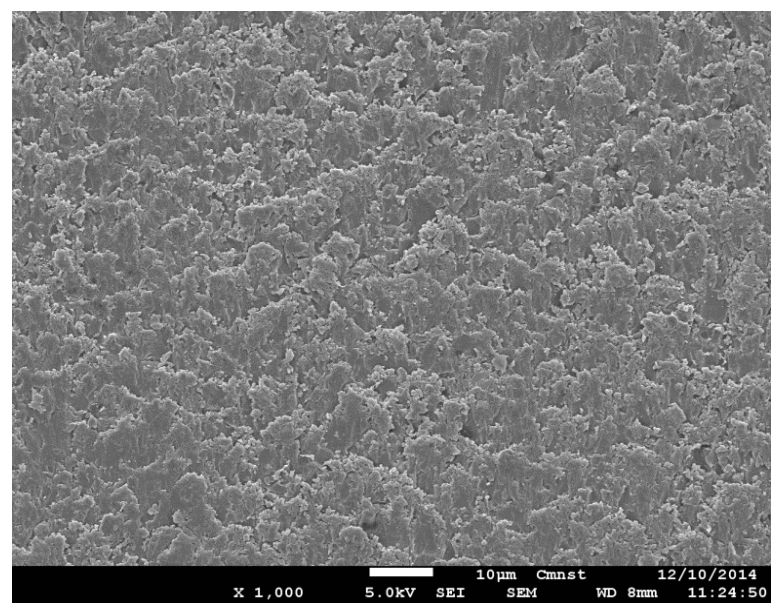

(b)

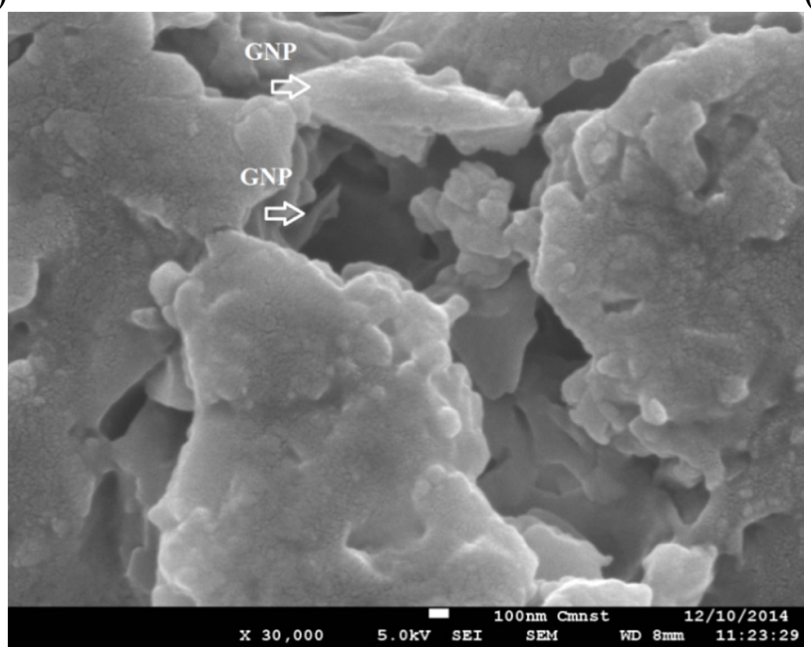

(c)

Figure 9. SEM graphs of (a) neat epoxy/polyester; (b) epoxy/polyester composite reinforced with $0.2 \%$ GNPs at a magnification of 1000; (c) epoxy/polyester composite reinforced with $0.2 \%$ GNPs at a magnification of 30,000 . 


\section{Conclusions}

This research used a nano-filler of GNPs to reinforce an epoxy/polyester blend. The tensile strength of the hybrid matrix nanocomposite reaches the maximum value with a very small amount of GNP filler added. When the weight percentage of the filler exceeded this determined value, the tensile strength of the nanocomposite decreased markedly and the material became brittle. The tensile strength of the GNP-reinforced epoxy/polyester blend nanocomposite reached approximately $86.8 \%$ with an addition of only $0.2 \%$ GNP content, as compared to neat epoxy/polyester. The DMA results indicated an improvement of up to $3100 \mathrm{MPa}$ in the storage modulus for the epoxy/polyester nanocomposite reinforced with $1 \mathrm{wt} \%$ GNPs. The TGA results confirmed the thermal stability of the resulting nanocomposite specimens, regardless of the weight percentage of the GNPs. Additionally, as observed in the SEM images, there was good adhesion between the fillers and the resin. Therefore, the novel materials created in this study were of high mechanical strength, good thermal conductivity and stability, and can be used to produce high-performance components which are light weight, high quality and low cost for applications in electronic circuit boards and transportation.

\section{Acknowledgments}

The authors acknowledge and thank the Ministry of Science and Technology of the Republic of China for their financial support of this study under Contract Number: MOST 103-2221-E-151-035.

\section{Author Contributions}

All the authors contributed significantly for the completions of this manuscript. Shyh-Chour Huang is the leader of the research group and responsible for supervising the experiments, writing and editing the article. Minh-Tai Le is mainly responsible for design and implementing of experiments, collecting, processing and analyzing the data as well as writing the main parts of the article.

\section{Conflicts of Interest}

The authors declare no conflict of interest.

\section{References}

1. Potts, J.R.; Dreyer, D.R.; Bielawski, C.W.; Ruoff, R.S. Graphene-based polymer nanocomposites. Polymer 2011, 52, 5-25. [CrossRef]

2. Li, J.; Guo, Z.J. The influence of polyethylene-polyamine surface treatment of carbon nanotube on the TPB and friction and wear behavior of thermoplastic polyimide composite. Polym. Plast. Technol. Eng. 2011, 50, 996-999. [CrossRef]

3. Chinnakkannu, K.C.; Muthukaruppan, A.; Josephine, S.R.; Periyannan, G. Thermo mechnical behaviour of unsaturated polyester toughened epoxy-clay hybrid nanocomposites. J. Polym. Res. 2007, 14, 319-328.

4. Shahryar, P.; Siddaramaiah, A.S.; Rajulu, A.V.; Kumar, S.V.; Rao, G.B. Tensile properties of glass roving's/hydroxyl terminated polyester toughened epoxy composites. Polym. Plast. Technol. Eng. 2011, 50, 973-982. 
5. Cherian, A.B.; Varghese, L.A.; Thachil, E.T. Epoxy-modified, unsaturated polyester hybrid networks. Eur. Polym. J. 2007, 43, 1460-1469. [CrossRef]

6. Tan, S.G.; Chow, W.S. Thermal properties, fracture toughness and water absorption of epoxy-palm oil blends. Polym. Plast. Technol. Eng. 2010, 49, 900-907. [CrossRef]

7. Zandiatashbar, A.; Picu, R.C.; Koratkar, N. Mechanical behavior of epoxy-graphene platelets nanocomposites. J. Eng. Mater. Technol. 2012, 134, 031011-031016. [CrossRef]

8. Yang, S.Y.; Lin, W.N.; Huang, Y.L.; Tien, H.W.; Wang, J.Y.; Ma, C.C.; Li, S.M. Synergetic effects of graphene platelets and carbon nanotubes on themechanical and thermal properties of epoxy composites. Carbon 2011, 49, 793-803. [CrossRef]

9. Ahmadi-Moghadam, B.; Taheri, F. Effect of processing parameters on the structure and multi-functional performance of epoxy/GNP-nanocomposite. J. Mater. Sci. 2014, 49, 6180-6190. [CrossRef]

10. Li, W.; Dichiara, A.; Bai, J. Carbon nanotube-graphene nanoplatelet hybrids as high-perfprmance multifunctional reinforcements in epoxy composites. Compos. Sci. Technol. 2013, 74, 221-227. [CrossRef]

11. Cui, W.; Du, F.; Zhao, J. Improving thermal conductivity while retaining high electrical resistivity of epoxy composites by incorporating silica-coatedmulti-walled carbon nanotubes. Carbon 2011, 49, 495-500. [CrossRef]

12. Viswanath, G.R.; Thangaraj, R.; Guhanathan, S. Thermomechanical and electrical studies on epoxy/hyperbranched polyester blends. Int. J. Polym. Anal. Charact. 2009, 14, 493-507. [CrossRef]

13. Rahman, M.M.; Zainuddin, S.; Hosur, M.V. Improvements in mechanical and thermo-mechanical properties of eglass/epoxy composites using amino functionalizedMWCNTs. Compos. Struct. 2012, 94, 2397-2406. [CrossRef]

14. Park, J.G.; Cheng, Q.; Lu, J. Thermal conductivity of MWCNT/epoxy composites: the effects of length, alignment and functionalization. Carbon 2012, 50, 2083-2090. [CrossRef]

15. Gojny, F.H.; Schulte, K. Functionalisation effect on the thermo-mechanical behaviour of multi-wall carbon nanotube/epoxy-composites. Compos. Sci. Technol. 2004, 64, 2303-2308. [CrossRef]

(C) 2015 by the authors; licensee MDPI, Basel, Switzerland. This article is an open access article distributed under the terms and conditions of the Creative Commons Attribution license (http://creativecommons.org/licenses/by/4.0/). 